\title{
The cognitive-pragmatic mechanism of metaphor generating and dying
}

\author{
Pan Zhenghua \\ College of Foreign Languages, China Three Gorges University, Yichang, 443002
}

Key words: metaphor; generating mechanism; cognitive-pragmatic; change

\begin{abstract}
This article re-defines metaphor and re-classifies metaphor and it maintains that the generating of metaphor is a result of the resultant force of many factors, including the cognitive factors and pragmatic factors working in a paralleled way. The generating and the dying of metaphors form two extremes of the continuum of metaphor.
\end{abstract}

\section{Introduction}

Metaphor, as a linguistic phenomenon, pervades in all our life, just as Lakoff and Johnson (1980) mentions, "[...] metaphor is pervasive in everyday life, not just in language but in thought and action”.Metaphor is regarded not only as a figure of speech but also as an in-built cognitive tool. The worldwide researches of metaphor mushroom.

Metaphor has been studied for a long time. Since the publication of Black's “interaction view of metaphor” (1962), scholars with different academic backgrounds have been engaged in the exploitation of mechanism of metaphor generation and comprehension, especially in the nature and function of metaphor in language and thought. The important books published include Metaphor and Thought (Ortony, 1979) and Cognition and Figurative Language (Honeck et al., 1980). In addition, important journals such as Metaphor and Symbolic Activity launched in 1986 were published. Meanwhile, the hurricane of metaphor has also swept China. A lot of authors have published books on metaphor, through which the theories of metaphor have been introduced into China and the solid foundation of metaphor studies have been laid down. Apart from some "old" generation who has done some research in cognitive linguistics like HU Zhuanglin, ZHOU Liuxi, XU Shenghuan, HE Ziran, and XIONG Xueliang, the new generation has come out. And the six doctoral theses by FAN Wenfang, WANG Songting, SHU Dingfang, YAN Shiqing, TIAN Xuejun and XU Zhanghong deserve our attention. And in the journals like Cognitive Psychology, Journal of Verbal Learning and Verbal Behavior, Journal of Pragmatics good quality papers are published successively. From all the papers published abroad and in China's key journals, a trend will be seen: the studies of metaphor have changed the direction from as figure of speech to from the perspective of pragmatic inference.

\section{The re-definition}

Different experts and scholarspropound the definitions of metaphor. These definitions are made from a special aspect of metaphor and based on different perceptions, but they reflect the inner insight.

Aristotle claims "Metaphor is the application to one thing of the name belonging to another. We may apply (a) the name of a genus to one of its species, or (b) the name of one species to its genus, or (c) the name of one species to another of the same genus, or (d) the transfer may be based on a proportion.” In this concise definition, which aspires to tie all the strands of metaphor into a 
coherent whole; the use of the words genus and species notifies us immediately that we are about to encounter a theory which is strongly rooted in the type hierarchy, a tradition which is still very much alive today in the computational treatment of metaphor. Metaphor is seen here as a conceptual phenomenon arising from the manipulation of the type hierarchy.... And we can obtain a somewhat conflicting view of metaphor from The Poetic and the Rhetoric. On one hand, Aristotle grants high cognitive status to metaphor in claiming that it is not an empty word game, but a vital (lively) process of communication and learning; but on the other hand, he undermines this elevated status by describing the metaphoric process in overly simplistic ontological terms.

Richards advocates that metaphor is the result of the interaction of two concepts. And as for many other theorists, albeit they have pointed out the nature of metaphor, they have not given a clear or satisfactory definition of metaphor.

TIAN Xuejun (2005), in his Ph.D. dissertation, gives his definition: metaphor is a linguistic resource/ means/ strategy for more effective communication.

Modern cognitive science holds that metaphor is essentially not only a phenomenon of a figure of speech, but a cognitive activity. It has potential and profound influences on the human's cognition, and contributes greatly to categorization and the forming of concept structure and the processing of inference. Metaphor is the tool and the result of cognitive activities, which jumps out of the limitation that metaphor arises from the comparison of two items on basis of similarities. Thus, metaphor caters for the needs of cognition and is the result of cognition, and pushes forward the development of cognition.

Comparing with the definitions or natures of different experts, we can see that the definitions still have not come to a union. But essentially, it is be of my opinion that they can be divided into two general kinds: one is that metaphor is regarded as static, and the other is that metaphor is regarded as dynamic. Of course, this distinction is relative. Without doubt, we can not say which one is better or even which one is right or wrong, because in each one there are some reasonable elements and some unreasonable ones as well. In this sense, if we capture well nigh all the reasonable elements, the definition will be comparatively perfect. Static one, we can say, focuses on the result, while the dynamic one focuses on the process. Thus, if we want to define metaphor with staticness and dynamism abstractly, we can say that metaphor is trying to use the "dynamic process" to achieve the "static result". In this way, we fuse the two different concepts together so that the theories will not be in conflict with each other and the merits of the previous definitions are fully made use of. As a result, we reconcile the two opposing aspects of metaphor definitions into a harmonious unity. Of course, if we define metaphor in that way, it only provides a frame for us to imagine. We have to fill in some contents so that the definition is with flesh and blood. We can tend to define metaphor as follows: metaphor is a tool for and a result of cognitive activities in which one concept is mapped to another and "mix" together in order to achieve an optimal communication. Now, it is the turn to explain the definition. In this definition, we have made use of the research findings in cognitive science.And the reason why we use a quotation mark on "mix" just because here "mix" is not a kind of mechanical merging, but very flexible. That is to say, when two concepts are put together, if the new meaning is obvious, it will stand out easily, but if it is not very obvious, it needs the hearer's initiative to figure out. So here the "mix" is not a simple and passive one. In addition, we use the word "map" to avoid using the conception that "metaphor is based on similarities" because metaphor is not only based on similarities, but can also create similarities. As for "optimal communication", we can use it to refer to the effect of figure of speech and other poetic effects. Therefore, in this definition, we can say that metaphor is using the dynamic process of mapping one concept to another in order to achieve the static result of an optimal 
communication.

\section{The classification of metaphor}

Metaphor can be divided according to different criteria. Aristotle divides metaphor into four kinds according to the manipulation between genus and species, which is the semantic manipulation between type hierarchies. Black (1979, cited in Xu, 2007) suggests that metaphor should be divided into three kinds: extinct metaphor, dormant metaphor, and active metaphor, and he is against the dichotomy: dead metaphor and live metaphor. Obviously, Black advocates that metaphor can be divided according to the degree of metaphoricalness and he is against that metaphor change is all of sudden, but gradual. Lakoff \& Johnson (1980) divide metaphor into three kinds: structural metaphor, orientational metaphor and ontological metaphor. And the last one can be subdivided into entity and substance metaphor, container metaphor, and personification. Actually, there is no special criterion in the classification of metaphor in Lakoff \& Johnson's classification. As for the structural metaphor, we can take "money" for example. The structure of "money" can be mapped onto "time" so that time can be saved, spent, wasted, invested, or even can be stolen. WANG Yin (2007) also takes “铁 屋子(iron house)” in “呐喊” for example. And for orientational metaphor, people will use the orientational word such as before, after, down, and so on to organize another concept. And the following sentences are the examples of the subtypes of ontological metaphor.

(4) A: What fur did Adam and Eve wear?

B: Bear skin.

From (4), we can see here "bear" is a homonym, which plays a key role in the activation of metaphor. At the first face, it means a kind of animal, but it actually means "nothing put on”, because Adam and Eve wear nothing in the Garden of Eden. Another example,

(5) A: Why are parliamentary reports called "blue books"?

B: Because they are never read.

In a similar way, here "read" and its homonym "red” work here. And this kind of phenomenon appears in Chinese as well.

To be short, the classification of metaphor can be done variedly. In light of the main ideas of metaphor from a cognitive point of view, metaphor is the result of mapping one conceptual domain to another. Meanwhile, we know that in Langacker's opinion a symbolic unit is represented by a semantic unit and a phonological unit. When two concepts are put together, they will interact and map to each other. And the concept of a symbolic unit is made of two: the semantic unit and phonological unit. Therefore, when they map to each other, there exist three kinds of situations: the first one should be both the semantic unit and the phonological unit take part in the mapping, the second and the third should be that either one of the two will participate in the mapping. And this will give an important inspiration for the classification of metaphor.

Generally, we might divide metaphor into two kinds: linguistic metaphor and entity metaphor. Linguistic metaphor refers to the metaphors used in language and entity metaphor refers to some metaphor indicated by gesture, sign and other non-linguistic metaphor. Linguistic metaphor will be mainly touched upon in this article but entity metaphor will be ignored. And linguistic metaphor can be subdivided into sentential metaphor and textual metaphor. But textual metaphor is not easy to manipulate and they are only the correspondence between form of the text and the contents of the world, which determines the textual metaphors are not rich in number. Consequently, the analysis of textual metaphor will be discarded in this article. As for the sentential metaphor, we further to divide it into semantic metaphor, and phonological metaphor according to the analysis in the last paragraph. Of course, it is possible that the two components of the symbolic units are mapped 
simultaneously. But they are out of the mainstream of metaphor, so they are out of our discussion. And the boundaries between the subdivisions are fuzzy.

To sum up, metaphor can be divided at different level, but we are concerned aboutsemantic metaphor and phonological metaphor. And we will talk about them in the following section. But first, we should know how to generate metaphor.

\section{The mechanism of metaphor generating}

As a speaker, we should know how to produce metaphors so that we make our opinions more beautifully and precisely expressed. And as a hearer, we should know how to make an inference from and understand metaphors. Only when these two conditions are met, can a communication be successful. How can this happen? Is there any mechanism to guide this? The answer might be "yes". We tend to put forward this mechanism. This mechanism may be universally in-built.

As suggested above, metaphor is the result of a resultant force of different factors. The factors are manifest. And now, we attempt to simplify the factors, capturing the key ones and merging some less important ones into one. According to the studies of metaphor, we can see that we can not say that the tenor and the vehicle of metaphor can be equal. They at least have something different, or else the metaphor can not be formed. Simultaneously, they should be at least "similar in spirit". The "similarity in spirit" can be already there or can be created by the speaker. Of course, the ideal metaphor is the one which can be similar both in spirit and form .

Figure 1 The mechanism of metaphor generating

And this kind of metaphor is the easiest to recognize by the hearer. Consequently, we can regard these as two factors which act on each other so that a balance can be achieved. Borrowing some ideas from the principles put forward by ZHANG Yuping et al. (1998), we can regard the two factors as Distance Principle and Relevance Principle respectively. In order to make the mechanism clearer and more intuitionistic, we will demonstrate the relationship between them in Figure 1.

We have divided metaphor into semantic metaphor, and phonological metaphor. It is generally held that a metaphor is formed by juxtaposing two different things to map one to the other. The inspiration of the means of creating metaphor might be got from Aristotle's semantic manipulation between the type hierarchy and the mapping of the components of Langacker's symbolic unit. Accordingly, people can form metaphor semantically and phonologically.

\section{The change of metaphor}

As studies have shown, metaphor is always changing. With the development of society and the network, the new concepts emerge endlessly. And because the metaphors have been used repeatedly, the new concepts will become "old", with the metaphor losing its metaphoricity and becoming one of the meanings of a word. The metaphor is conventionalized or dead or, we can say, fossilized. And through this process, the meanings of the word are enriched. Why does this happen? We may be able to explain the reason, making use of the Semantic Triangle by Ogden. Now we just adapt the triangle a little bit. We replace symbol with tenor, referent with vehicle; we can understand the relationship between tenor and vehicle through inference and get the meaning of the metaphor. That is, the meaning of the metaphor goes through two laterals, more time and more effort being used. But if a metaphor has been overused, the meaning of metaphor will go through the dot line. If so, the distance will disappear, and metaphorical meaning will vaporize as well and change into a kind 
of super-symbolic meaning, a shared knowledge between speakers and listeners.

The process of the change of metaphor can also be demonstrated with Figure 3. In Figure 3, the process of the change of metaphor is not all of sudden, but gradual. We can compare the tenor and the vehicle of the metaphor to two circles. At first, the two circles representing two different conceptions are apart. When they are juxtaposed, the interaction between them will happen and they are expected to be relevant but still have distance. Step by step, they are more relevant with less distance when metaphor is overused until they overlap. If so, the metaphor dies and the meaning of the vehicle becomes one of the meanings of the tenor. And sometimes the "dead metaphor" can come back to life under certain conditions.

We can not draw a clear line between metaphor and non-metaphor. There are no criteria for us to do so, either. We can only say that the metaphor of the same tenor and the same vehicle form a continuum when it changes as the time elapses. We can suppose that at one end is the Relevance, and at the other end is Constriction. We use $\mathrm{R}$ and $\mathrm{C}$ to represent each other respectively in Figure 4. When the metaphor is just in the middle of the continuum, its metaphoricity will be the strongest and it is the easiest for the hearer to detect the metaphor and interpret. If the metaphor moves from the middle towards $\mathrm{R}$, the metaphoricity will be less and less strong and when it arrives at the critical point of Relevance, the metaphoricity will disappear and the metaphorical meaning becomes one of the meaning entries of a word. On the other hand, when the metaphor moves towards $\mathrm{C}$, it will become harder and harder for the hearer to figure out the metaphor. And when the metaphor goes beyond $\mathrm{C}$, the metaphor is not metaphor at all and there is no relationship between the tenor and the vehicle. It is in the state of being apart just demonstrated in Figure 3.

Herein, we can attribute the change of metaphor to the competing of Relevance force and Constriction force. From $\mathrm{C}$ to $\mathrm{R}$, the metaphor is becoming easier and easier to figure out until it becomes one entry of the word meanings. But from $\mathrm{R}$ to $\mathrm{C}$, we will find more effort will be used to figure out the metaphor, but more pleasure will be obtained as it is approaching the point $\mathrm{C}$ as long as it does not cross over the crucial point $\mathrm{C}$.

In short, the change of metaphor is a fact. All the explanations above are just tentative. The change of metaphor is not the result of only one or two forces listed, but acted on by many factors. Above, we have talked about the change from three perspectives: linguistic habits, the manners of changing, and the rules guiding the change. And from that we can know that the change of metaphor is gradual, guided by Relevance and Constriction forces and many other factors. And the change is generally one-directional, from $\mathrm{C}$ to $\mathrm{R}$ until it turns into one part of the word meanings.

\section{Conclusion}

We can see that metaphor is not only a figure of speech, but a cognitive tool. We can divide metaphor into semantic and phonological metaphorsand we can create metaphor semantically and phonologically. Metaphor's generating is guided by many cognitive-pragmatic factors. Metaphor will finally be conventionalized and die gradually.

\section{References:}

[1] Black, M. 1962. Models and Metaphors [M]. Ithaca, NY: Cornell University Press.

[2] Chalker, S. \& E. Weiner. 1994/1998. Oxford Dictionary of English Grammar [M]. Oxford University Press.

[3] Langacker, R.W. 1987. Foundations of Cognitive Grammar vol. I: Theoretical Prerequisites[M]. Stanford, California: Stanford University Press. 
[4] Tian, Xuejun. 2005. Manipulating Metaphor for More Effective Communication-Metaphor in the Pragmatic Perspective [D]. Beijing Normal University. (unpublished)

[5] Xu, Zhanghong. 2007. Metaphor Understanding: A Pragma-Cognitive Approach [M]. Beijing: Science Press.

[6] Zhang, Yuping., Jiang, Yanping. \& Yu, Nianhu. 1998. Euphemism [M].Beijing: Xinhua Press. 